\title{
MEMBANGKITKAN SEMANGAT BELAJAR AGAMA SEJAK DINI DAN MELAKUKAN KEGIATAN KEAGAMAAN TAMAN PENDIDIKIAN AL-QUR'AN (TPQ)
}

\author{
Ahsani Taqwiem, Kundrianingsih \\ Fakultas Ekonomi dan Bisnis, Universitas Islam Malang \\ *korespondensi email: ahsani.taqwim@unisma.ac.id
}

\begin{abstract}
ABSTRAK
Belajar mengenai ilmu agama memang perlu ditanamkan sejak dini. Pendidikan akan dasar keagamaan harus diberikan kepada anak sedini mungkin, oleh karena itu anak sangat membutuhkan pendidikan, binaan, arahan serta bimbingan dari berbagai pihak yaitu salah satunya antisipasi orang tua dalam memberikan pendidikan keagamaan kepada anakanaknya dengan cara mengikutsertakan dalam kegiatan Taman Pendidikan Al-qur'an (TPQ) dan juga peran masyarakat dan juga lembaga pendidikan. Tujuan dari membangkitkan semangat belajar agama dari bimbingan dan pembinaan tersebut adalah agar kepribadian dan fitrah keberagamaan yang ada pada diri seorang anak bisa terarah dengan baik dan sesuai dengan tuntunan ajaran agama. Oleh karena itu pendidikan akan dasar keagaaman harus diberikan kepada anak sedini mungkin. Karena pendidikan yang dilakukan sejak dini akan lebih mengena dan meresap dalam jiwa anak untuk semangat dalam belajar agama.
\end{abstract}

Kata Kunci: semangat belajar agama; kegiatan keagaaman

\section{PENDAHULUAN}

Taman Pendidikan Al-Qur'an (disingkat TPA atau TPQ) adalah lembaga atau kelompok masyarakat yang menyelenggarakan pendidikan nonformal jenis keagaaman Islam yang bertujuan untuk memberikan pengajaran membaca AL-Qur'an sejak usia dini (Malik, 2013; Muntoha et al., 2015), serta memahami dasar-dasar Islam pada anak usia taman kanak-kanak, sekolah dasar dan atau madrasah ibtidaiyah (SD/MI) atau bahkan yang lebih tinggi. TPA/TPQ setara dengan RA dan taman kanak-kanak (TK), di mana kurikulumnya ditekankan pada pemberian dasar-dasar membaca AL-Qur'an serta membantu pertumbuhan dan perkembangan anak agar memiliki kesiapan dalam memasuki pendidikan lebih lanjut (Gunawan, 2011).

Oleh karena itu pendidikan dan juga memberi semangat belajar mengaji sejak dini sangat perlu untuk anak-anak karena mereka perlu mendapatkan perhatian untuk menjadi generasi yang tangguh, beriman, berakhlak mulia dan pandai bersyukur. Dan orang tua serta generasi muda sekarang harus mendukung kegiatan-kegiatan dalam keagamaan untuk membangkitkan semangat anak-anak untuk belajar agama (Aristanto et al., 2020; Hidayah et al., 2019).

Pembinaan atau membangkitkan semangat belajar agama sejak dini sudah seharusnya diberikan kepada anak-anak sedini mungkin, karena pembinaan atau pendidikan yang diberikan pada masa kecil pengaruhnya akan lebih tajam atau berbekas dari pada pendidikan yang diberikan pada usia dewasa (Aristanto et al., 2020; Maulidiyah, 2018). Untuk melaksanakan pendidikan agama tidak hanya terletak pada lembaga formal 
(sekolah) saja, tetapi keluarga, dan juga lembaga-lembaga pendidikan di lingkungan masyarakat, misalnya Taman Pendidikan AL-Quran'an (TPQ) yang diman TPQ adalah salah satu lembaga yang dapat berperan aktif meningkatkan pendidikan agama.

Meningkatkan semangat belajar agama sejak dini sebagai suatu instansi, Taman Pendidikan AL-Qur'an (TPQ) mempunyai suatu strategi atau pendekatan pembinaan yang bukan hanya semata-mata pengajaran saja, akan tetapi juga pendidikan atau pembinaan agama lebih diarahkan dalam membentuk dan membina peserta didik Taman Pendidikan AL-Qur'an untuk menjadi muslim yang sejati dan benar-benar menghayati nilai-nilai agama dan mengindahkan norma-norma dalam kehidupan sehari-hari. Ilmu agama yang diberikan bukan sekedar sebagai suatu ilmu tetapi sebagai perangkat penunjang untuk membentuk pribadi-pribadi muslim. Dengan kata lain pembelajaran agama bukan diarahkan pada bagaimana anak menjadi seoarang ahli agama, tetapi pembinaan dan memberikan semanagat belajan mengikuti kegiataan keagamaan lebih diarahkan pada bagaimana santri menjadi agamawan yang baik.

\section{METODE}

Dalam mencapai tujuan yang diharapkan metode yang digunakan dalam pengabdian ini adalah metode pembelajaran dan meningkatkan semangat belajar agama sejak dini. Program KSM-Tematik ini dilaksanakan di Taman Pendidikan AL-Qur'an (TPQ) Idhar Rusurul RT 08 RW 02 Desa Grandeng, Kecamatan Lolong Guba, Kabupaten Buru Maluku.

Sasaran yang dipilih adalah masyarakat khususnya anak-anak. Penetapan sasaran ini merupakan suatu upaya untuk meningkatkan semangat belajar agama sejak dini harapannya bertujuan untuk memberikan semangat dalam belajar agama dan juga mengikuti kegiatan-kegiatan keagamaan pada masyarakat khususnya anak-anak.

Ada beberapa tahapan-tahapan yang dilakukan dalam pelaksanaan program yaitu sebagai berikut (1) Koordinasi melakukan kegiatan kepada pendiri TPQ, (2) melakukan pendampingan belajar mengaji, (3) mengadakan kegiatan kagaamaan lomba cerdas cermat yang dimana bertujuan untuk memberikan semangat belajar mengaji, (4) pembelajaran AlQur'an dan juga memberikan perhatian langsung pada tiap-tiap anak supaya anak-anak lebih jelas dan paham dalam belajar.

\section{HASIL DAN PEMBAHASAN}

Meningkatkan semangat belajar agama sejak dini dan mengikuti kegiatan keagamaan adalah suatau alat penunjang dari suatu proses pembelajaran dari suatu proses pembelajaran yang diberikan dalam kegiatan belajar mengaji sehingga anak-anak dapat menerapkan agama dan semngat belajar dalam kehidupan sehari-hari (Kusnadi et al., 2018).

Dalam kegiatan tersebut ada sebagian kendala pada anak-anak yang masih malas dan acuh tau dalam pembelajaran tersebut, tetapi kita tidak tinggal diam saja kami selalu berusaha meningkatkan semangat belajar kepada anak-anak dengan cara mengenal lebih dekat karakter anak-anak dan juga kami memberikan kegiatan-kegiatan seperti mengadakan lomba cerdas cermat dan membaca sholawat bersama sehingga anak-anak tidak merasa bosan dalam melakukan kegiatan agama. Dan respon positif pada anak-anak Taman Pendidikan Al-Qur'an (TPQ) Idhar Rusurul sangat membantu kegiatan tersebut sehingga kegiatan ini berjalan dengan lancar dan semestinya.

Dengan terlaksanaanya kegiatan meningkatkan semangat belajar mengaji anak-anak Taman Pendidikan Al-Qur'an (TPQ) tersebut mereka mulai rajin masuk dan juga lebih semangat dalam mengikuti kegiatan-kegiatan keagamaan yg di adakan di TPQ tersebut. Peran aktif orang tua juga sangat penting dalam mengembangkan karakteristik anak sejak dini. 
Taqwiem, A., Kundrianingsih

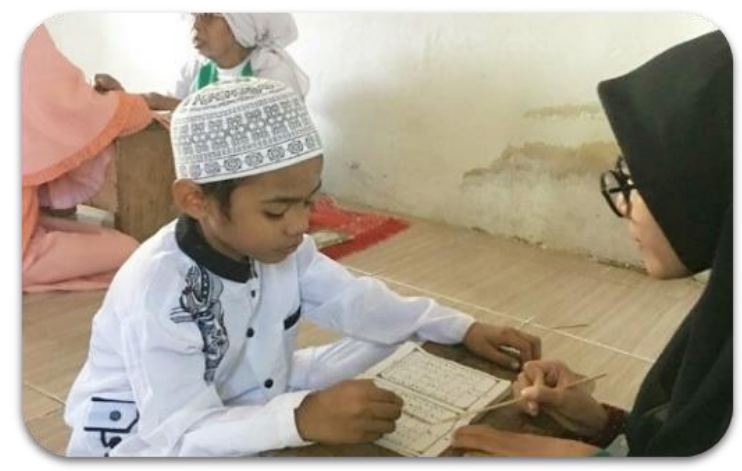

Gambar 1. Pendampingan belajar mengaji

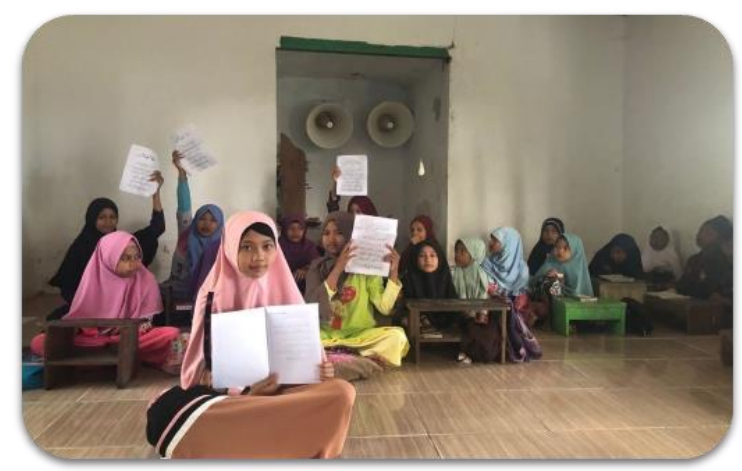

Gambar 2. Menulis dan menghafal sholawat Nuril Anwar untuk diterapkan dalam kehidupan sehar-hari

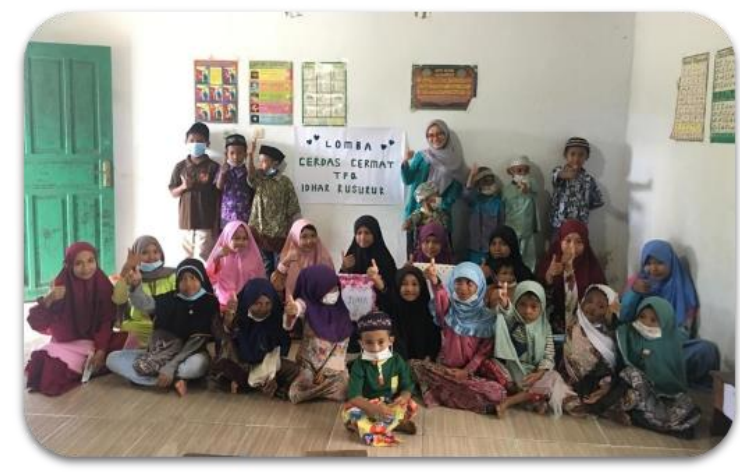

Gambar 3. Foto Bersama dengan anak-anak TPQ Idhar Rusurul

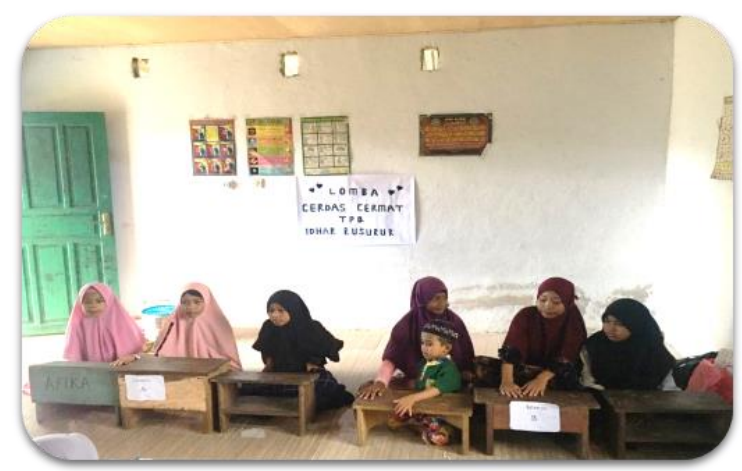

Gambar 4. Melakukan kegiatan lomba cerdas cermat 


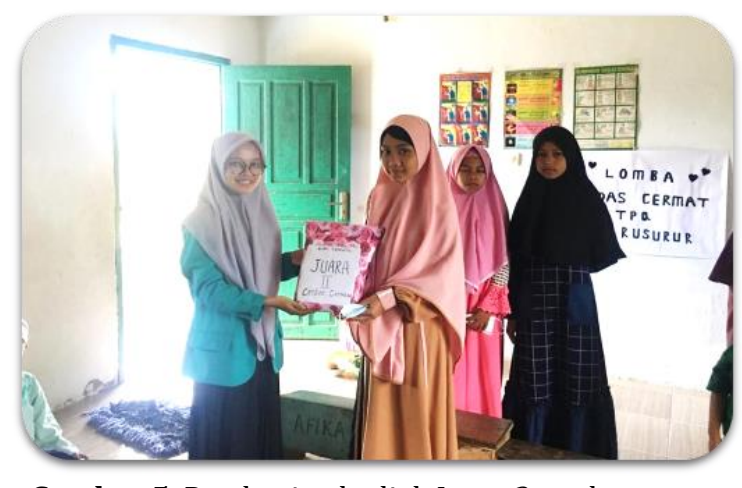

Gambar 5. Pembagian hadiah Juara 2 cerdas cermat

\section{KESIMPULAN}

Dalam kegiatan meningkatan semangat belajar mengaji sejak dini dan mengikuti kegiatan keagamaan yang dilaksanakan oleh Mahasiswa KSM-Tematik Universitas Islam Malang sangat mendapat sambutan postif dari pendiri TPQ dan juga anak-anak TPQ, pembinaan yang dilakukan di TPQ Idhar Rusurul yang sedikit ada kendala dari anak-anak yang malas hadir anak-anak yang masih ingin bermain kendala yang Mahasiswa hadapai hanyalah harus mengendalikan keaktivian anak-anak dengan memberika arahan-arahan bahwa belajar mengaji sangat penting dan semangat anak-anak dalam belajar agama juga sangat penting untuk diterapkan. Dan semoga dengan berjalannya kegiatan tersebut kami berharap anak-anak TPQ Idhar Rusurul dapat semangat lagi dalam belajar agama rajin masuk dan semangat dalam mengikuti kegiatan-kegiatan yang dilaksanakan dengan pendiri TPQ atau Mahasiswa yang melakukan kegiatan KKN di TPQ ataupun kegiatan keagamaan lainnya.

\section{UCAPAN TERIMA KASIH}

Ucapan terima kasih di sampaikan kepada Kepala Desa Grandeng dan Masyarakat dan juga pendiri TPQ Idhar Rusurul yang sudah memberikan kami ijin melakukan kegiatankegitan di Desa Grandeng, kepada Universitas Islam Malang atas kesempatan yang di berikan kepada kami para mahasiswa untuk dapat melakukan kegiatan pengabdian kepada masyarakat atau KSM-Tematik ini. Serta terimakasih kami ucapkan kepada Pendiri TPQ yang sudah membantu dan mendukung terlaksananya kegiatan Kandidat Sarjana Mengabdi KSMTematik. Teriring doa semoga Allah SWT selalu melindungi dan merahmati kita semua.

\section{DAFTAR RUJUKAN}

Aristanto, E., Hidayatullah, S., Rachmawati, I. K., Waris, A., \& Khalikussabir. (2020). Peningkatan Fasilitas Bagi Tahfizh Anak Usia Dini "Kuttab Rumah Quran" Menuju Persaingan Pendidikan Anak Pra Sekolah. Jurnal Inovasi Hasil Pengabdian Masyarakat (JIPEMAS), 3(1), 78-86. https://doi.org/10.33474/jipemas.v3i1.4763

Gunawan, A. (2011). Pendidikan Karakter Berbasis Taman Pendidikan Al-Qur'an (TPA/TPQ).

Kompasiana. https://www.kompasiana.com/arygunawan/5500dfbda333117c6f5124af/pendidi kan-karakter-berbasis-taman-pendidikan-al-qur-an-tpa-tpq

Hidayah, Y., Suyitno, \& Retnasari, L. (2019). Pemberdayaan Taman Pendidikan Al-Quran (TPA) Sebagai Pusat Pendidikan Karakter Religus ( Pengabdian di TPQ Silastra Condong Catur, TPQ Darul Falah Maguwo Harjo. LOYALITAS Jurnal Pengabdian Kepada Masyarakat, 2(2), 13-20. https://doi.org/10.30739/loyal.v2i2.489

Kusnadi, D., Fattah, N., Husaini, A., \& Ruhenda, R. (2018). Efektivitas Implementasi Kebijakan Penilaian Autentik pada Pembelajaran Pendidikan Agama Islam. Ta'dibuna: Jurnal 
Pendidikan Islam, 7(1), 20. https://doi.org/10.32832/tadibuna.v7i1.1348

Malik, H. A. (2013). Pemberdayaan Taman Pendidikan Al-Qur'an (TPQ) ALhusna Pasadena Semarang. Dimas: Jurnal Pemikiran Agama Untuk Pemberdayaan, 13(2), 387-404. https://doi.org/10.21580/dms.2013.132.60

Maulidiyah, E. C. (2018). Penanaman Nilai-Nilai Agama Dalam Pendidikan Anak Di Era Digital. Martabat: Jurnal Perempuan Dan Anak, 2(1). https://doi.org/10.21274/martabat.2018.2.1.71-90

Muntoha, Jamroni, Khoiruzaad, M., Prasetyo, H., Wijaya, M. A., Jabbar, A. A., U., R. U., A.W., D. A., P, D. I., \& Tantria, H. (2015). Pembinaan Taman Pendidikan Al-Qur'an (TPA) di Dusun Sangbanyu 1, Kecamatan Giri Subo, Gunung Kidul, Daerah Istimewa Yogyakarta. Jurnal Inovasi Dan Kewirausahaan, 4(3), 200-205. 